\title{
Interdisciplinaridade: 0 ensino de ciências por meio da literatura infantil ${ }^{1}$
}

\author{
Josiele Kaminski Corso Ozelame* \\ Diego Machado Ozelame* \\ João Bernardes da Rocha Filho ${ }^{* * *}$
}

\section{Resumo}

O objetivo deste trabalho é trazer à discussão a possibilidade de construir uma prática no ensino de ciências que contemple atividades prazerosas de descoberta, experimentação e exploração de conhecimentos científicos a partir da literatura. Acreditamos que o ensino de ciências aliado a diferentes abordagens de trabalho despertem nos estudantes o desejo pelo conhecimento científico e a descoberta do novo. Para isso, analisamos a obra infantil, Bichos que existem e bichos que não existem (NESTROVSKI, 2002), em que o escritor apresenta, por meio de uma linguagem poética, a descrição desses "seres" que habitam nossa memória, desde o jabuti até o lobisomem. Por meio da dúvida, da (des)construção dessas informações é que o leitor tem a possibilidade de transformar o abstrato em concreto, construindo diferentes espaços de interpretação, articulando a história ficcional ao conhecimento da biologia. Nesse sentido, buscamos assegurar e sugerir que o aprendizado de ciências, uma vez abordado de forma menos tradicional, como por meio do discurso literário, apresenta um pensamento mais condizente com a necessária renovação no ensino de ciências.

Palavras-chave: Ciências e literatura infantil. Interdisciplinaridade. Ensino.

\section{Introdução}

A literatura infantil, nos primeiros anos escolares, pode ser considerada uma poderosa ferramenta para o ensino de ciências ou, como se referem Lorenzetti e Delizoicov (2001), uma forma para a construção da alfabetização científica. Por

\author{
Recebido: 14/05/2015 - Aprovado: 07/01/2016 \\ http://dx.doi.org/10.5335/rep.v23i1.6363
}

Doutora em Literatura, professora e pesquisadora do PPG em Sociedade, Cultura e Fronteiras da Universidade Estadual do Oeste do Paraná - Campus Foz do Iguaçu, PR. E-mail: josicorso@gmail.com

** Doutorando do PPG de Ensino de Ciências e Educação Matemática da Universidade Estadual de Londrina. E-mail: diegozelame@gmail.com

*** Pós-doutor em Enseñanza de las Ciencias (Facultad de Educación/PUC Chile). Professor e pesquisador do PPG de Educação em Ciências e Matemática da PUCRS. E-mail: jbrfilho@pucrs.br 
meio da subjetividade, que desenvolve a curiosidade dos pequenos, as aulas podem ser enriquecidas com a ampliação das experiências, uma vez que o contato com temas científicos, por meio da linguagem ficcional, proporciona a reflexão e o debate, levando ao desenvolvimento da consciência crítica por meio da interlocução entre as ciências e as humanidades.

Porém, nem sempre a literatura teve seu papel na vida dos pequenos. Os primeiros livros escritos para crianças surgiram no final do século XVII e durante o século XVIII, pois, até então, não existia a ideia de infância como etapa diferenciada no desenvolvimento humano. Crianças eram vistas como adultos em miniaturas, e não havia um espaço no mundo burguês próprio para elas. Adultos e crianças frequentavam os mesmos lugares e eventos, sem nenhum laço distintivo. Os textos desse período eram dotados de moralidade, como se observa em As aventuras de Telêmaco e Os contos da Mamãe Gansa, de Perrault.

As primeiras obras destinadas às crianças foram escritas por pedagogos e professoras, o que atribuiu o caráter educativo às produções que permanece até hoje, uma vez que "não é aceita como arte, por ter uma finalidade pragmática; e a presença do objetivo didático faz com que ela participe de uma atividade comprometida com a dominação da criança" (ZILBERMAN, 2003, p. 16).

Com o êxodo rural, as fábricas a todo vapor, o surgimento das desigualdades sociais, a marginalização e o desemprego, se fortalece a classe social burguesa, que tem como objetivo ampliar espaço e poder. Seu principal alvo é a família, mais especificamente a criança. Essas mudanças ocorridas no século XVIII fizeram com que surgisse um novo modelo de família, mais doméstico e privado, em que a mãe cuida do lar, o pai cuida do sustento e a criança passa a ter estabelecido um lugar próprio e distinto na sociedade.

Entretanto, é na metade do século XX que surge o trabalho com a linguagem literária, visando um público específico (sem objetivo moralizante/didático): inicia-se a configuração da literatura infantil/juvenil no país. Concordamos com Ana Maria Machado (1999), quando afirma que o importante é o substantivo - literatura -, e não o adjetivo - infantil. Contudo, até pouco tempo, os livros eram para instruir os pequenos, não objetivando o deleite, a fruição e a construção de significados por meio da subjetividade.

\section{0 poder da literatura}

Para Ítalo Calvino (2011), há coisas que só a literatura pode nos dar por seus meios específicos. Nesse sentido, é possível perceber a importância do diálogo interdisciplinar entre literatura e ciências para a construção do conhecimento crítico. 
Já assinalava Zola que os romances diziam muito sobre o homem, muito mais que grandes obras da filosofia, eles "nos ensinam mais sobre a vida do que longos tratados científicos" (1982 apud COMPAGNON, 2009, p. 31).

Sobre a literatura, o crítico chama nossa atenção para a diferença e a disputa entre as letras e as ciências no início no século XIX, quando Bonald assegurou que as letras tinham ciúmes das ciências e seus progressos. Aquelas acreditavam que essas eram regidas por ambição desmedida, disputando o papel da moral, que era sempre atribuído às ciências, em função do prestígio maior.

Em oposição ao aspecto apresentado, no curso da história, a literatura exerceu poder de pertinência. Segundo Compagnon (2009), ela ajudou a viver, apresentando a vida mais simples e mais fácil, tornando o homem e a vida melhor. Para o autor, a literatura é importante por dar explicações familiares, podendo o homem aprender por meio da ficção. Ela deleita e instrui, desata o ser humano da alienação, serve como instrumento de justiça, de libertação, contesta a submissão ao poder. O crítico também acredita que é por meio da linguagem que temos a possibilidade de "exprimir o contínuo, o impulso e a direção, ou seja, sugerir a vida" (COMPAGNON, 2009, p. 46).

Recusar o poder da literatura, conforme atesta Compagnon, é atribuir-lhe apenas o papel recreacional, que visa apenas o prazer lúdico, conforme abordagem feita em muitas escolas. Frequentemente, essas instituições acabam por depreciar a literatura, reduzindo-a apenas a textos como pretextos de ensino. Já observava Calvino, e Compagnon retoma esta reflexão, que a literatura vai muito além da libertação de poder e ensino, e que é muito mais fácil ignorá-la que trabalhar com ela. Porém, o que ela ensina são formas de:

$[\ldots]$ ver o próximo e si mesmo, [...] de atribuir valor às coisas pequenas ou grandes, [...] de encontrar as proporções da vida, e o lugar do amor nela, e sua força e seu ritmo, e o lugar da morte, a maneira de pensar e de não pensar nela, e outras coisas 'necessárias e difíceis' como a 'rudeza, a piedade, a tristeza, a ironia, o humor (COMPAGNON, 2009, p. 57).

Nesse sentido, a literatura pode ser ensinada e lida na escola porque é um meio de repassar experiências para os outros, mesmo que distantes, diferindo em contextos e condições de vida. Ela proporciona o olhar de que "Os outros são muito diversos e que seus valores se distanciam dos nossos" (COMPAGNON, 2009, p. 60).

Assim, Carlos Ceia (2012) observa que a literatura é fonte de conhecimento indispensável ao ser humano e à formação da moral. Conforme o autor, quando olhamos para o mundo por meio de obras literárias compreendemos a realidade que ocupamos e a função que desempenhamos socialmente. Menciona em seu texto que hoje o ensino da ética em Ciências Econômicas e Políticas está atrelado às obras literárias. Portanto, segundo o teórico, o estudo da literatura é interdisciplinar. 
A literatura, por meio da leitura, "percorre regiões da experiência que os outros discursos negligenciam, mas que a ficção reconhece em seus detalhes" (COMPAGNON, 2009, p. 64).

Maurício Silva (2010) assinala que a leitura, como uma forma de apreensão da realidade, tem perdido seu espaço em detrimento de outras formas no seu mundo contemporâneo. Isso se reflete no momento de análise e interpretação textual em que apresentam grande dificuldade. Assim, a falta de leitura da literatura na escola é um dado a ser observado, uma vez que o diálogo interdisciplinar entre literatura e ciências proporciona condições de aprendizagem por meio da socialização do conhecimento, estimulando as manifestações interculturais. Nesse mesmo sentido, Edgar Morin (2011) observa que a inteligência e seu desenvolvimento não são separáveis do mundo afetivo, ou seja, caminham juntas cientificamente.

De acordo com Silva, "[...] considerar a literatura como área articuladora de aspectos diversos do conhecimento, promovendo a interdisciplinaridade, são alguns dos propósitos que uma política de promoção da leitura consciente e socialmente responsável deve buscar atingir" (2010, p. 5).

Sobre o poder da literatura nas aulas, na interação com outras áreas, podemos recorrer a Todorov (2009), que afirma que a literatura proporciona um leque de possibilidades, nos torna mais próximos de outros seres humanos, nos auxilia a compreender melhor o mundo, nos ajuda a viver. Ela revela o mundo e nos transforma de fora para dentro.

Aliar a leitura da obra de Bichos que existem e bichos que não existem, de Arthur Nestrovski (2002), às aulas de ciências, por exemplo, resgata a capacidade de pensar criativamente o mundo real, concreto, humanizado. Sob a luz de Compagnon: "[...] com a literatura, o concreto substitui ao abstrato e o exemplo à experiência para inspirar as máximas gerais ou, ao menos, uma conduta em conformidade com tais máximas" (2009, p. 33). Resgatando essa proximidade entre ciências e literatura, o autor observa ainda que as obras literárias falam muito sobre o homem e a natureza, e que por muito tempo a literatura respondeu a "um projeto de conhecimento do homem e do mundo. [...] Tal foi por muito tempo a justificativa da leitura ordinária e a premissa da erudição literária. A ciência as desqualificou? É o que parece" (2009, p. 26).

Outro exemplo de interdisciplinaridade entre literatura e ciências, já em um nível mais adequado para estudantes de ensino médio ou superior, pode ser encontrado na obra de Beltrão e Rocha Filho (2011), que exploraram as obras de Clarice Lispector em busca da compreensão de seu processo de individuação e o relacionaram com a física moderna. Nesse livro, as personagens de Clarice são interpretadas à luz da psicologia analítica, e se misturam com os mitos, os arquétipos 
e as leis da física, para construir uma perspectiva transcendente da trajetória da escritora. A partir desse texto, um professor disposto a iniciar um diálogo interdisciplinar entre literatura e ciência pode usar a psicologia analítica para construir pontes, pois a partir dela é possível compreender no humano a ideia do divino e o desenvolvimento das leis naturais estudadas nas ciências. Frente às muitas deficiências do ensino de física contemporâneo, essa pode ser uma alternativa para atrair a atenção dos estudantes, motivando-os a estudar ciências em uma reflexão complexa e permeada de ligações entre o real e o imaginário.

Aliar as duas disciplinas, ciências e literatura, permite em tempo e espaço a elaboração do conhecimento "individual e coletivo, subjetivo e objetivo, e que se estabelece como uma nova visão sobre a verdade do mundo e do homem" (CEIA, 2012, p. 176).

O livro de Arthur Nestrovski evoca o lúdico, a brincadeira, as crenças do povo, e desde cedo os estudantes aprendem a se relacionar e atribuem sentidos aos objetos à sua volta. A literatura também pode ser contemplada dessa forma, uma vez que a criança se delicia com histórias e poemas, estimulando a imaginação por meio do jogo da linguagem em diferentes níveis. Ao brincar com a existência ou não de alguns bichos, Nestrovski possibilita a criação/incorporação de novos sentidos à vida, significando e ressignificando a experiência.

É por meio da ludicidade, da fantasia, que a criança estabelece relações com a realidade que a cerca. A literatura proporciona a atribuição de sentidos às coisas, à vida. Em muitas práticas de ensino em sala de aula, acontecem a decoreba de termos e a memorização, a literatura, ao contrário, trabalha com a apropriação dos sentidos e a construção de significados, em que o leitor faz uso do texto, torna-se criador, interagindo com o texto, estabelecendo relações com o seu mundo.

\section{Ensino de ciências}

Furman (2009) afirma que, ao ensinar ciências, o professor coloca-se em uma situação de muita responsabilidade, pois a didática estabelece para os estudantes a necessidade de aprender a resolver problemas, analisar informações e desenvolver competências, de modo a prepará-los para os desafios impostos pela vida. Nessa perspectiva, a autora sugere que o professor tem o papel de "estimular a curiosidade que o aluno já traz consigo como plataforma sobre a qual estabelecer as bases do pensamento científico e desenvolver o prazer por continuar aprendendo" (2009, p. 7).

Nesse sentido, Furman assegura que, para o ensino de ciências, deve-se "utilizar esse desejo natural de conhecer o mundo que todos os alunos trazem para a 
escola como plataforma sobre a qual possam construir ferramentas de pensamento que lhes permitam compreender como as coisas funcionam, e pensar por eles mesmos" (2009, p. 7). No que tange ao mundo educacional, não diferente das questões sociais, a pesquisadora faz um alerta:

O que acontece se essas pedras fundamentais do pensamento científico não forem colocadas a tempo? Pensemos, por um momento, em alunos que saem do Ensino Fundamental sem a possibilidade de (nem a confiança para) formular maneiras de procurar respostas às coisas que não conhecem, ou de dar-se conta se há evidências que sustentam o que ouvem. Ou em alunos cuja curiosidade foi se apagando pouco a pouco por não terem encontrado espaço para expressá-la. Claramente estamos diante de um cenário muito arriscado, principalmente se pensarmos em construir uma sociedade participativa, com as ferramentas necessárias para gerar ideias próprias e decidir seu rumo (FURMAN, 2009, p. 7).

Em contrapartida ao modelo de educação linear, que privilegia um conhecimento compartimentado, que não incentiva a interação, as subjetividades, e suprimem a curiosidade dos estudantes, surgem pressupostos epistemológicos que apresentam um novo olhar sobre as ciências, como forma de crítica ao pensamento atual. Como exemplo, podemos citar Feyerabend, quando afirma que:

[...] a educação científica, tal como hoje conhecemos, tem precisamente esse objetivo. Simplifica a ciência, simplificando seus elementos: antes de tudo, define-se um campo de pesquisa; esse campo de pesquisa é desligado do resto da História (a Física, por exemplo, é separada da Metafísica e da Teologia) e recebe uma "lógica" própria. Um treinamento completo, nesse tipo de "lógica", leva ao condicionamento dos que trabalham no campo delimitado; isso torna mais uniformes as ações de tais pessoas, ao mesmo tempo em que congela grandes porções do processo histórico (2007, p. 7).

Nesse contexto, Morin (2000) defende que devemos priorizar uma organização de pensamento que permita fazer ligações entre as coisas, em vez de praticar a separação. $O$ autor considera imprescindível que as disciplinas não sejam fechadas em si mesmas, fragmentando os conteúdos, pelo contrário, devemos favorecer uma ação que privilegie a integração. Assim, a educação deve estimular a capacidade natural da mente em resolver problemas e saber relacioná-los com a totalidade. A realidade não é mais vista como um objeto imutável, mas como um processo de construção. Por esse motivo, o princípio da complexidade é fundamentado pelas relações entre as partes, pelas incertezas, pela continuidade e descontinuidade. Conforme Morin:

[...] as realidades globais e complexas fragmentavam-se, o humano desloca-se; sua dimensão biológica, inclusive o cérebro, é encerrada nos departamentos de biologia; suas dimensões psíquica, social, religiosa e econômica são ao mesmo tempo relegadas e separadas uma das outras nos departamentos de ciências humanas; seus caracteres subjetivos, existenciais, poéticos encontram-se confinados nos departamentos de literatura e poesia (2000, p. 40). 
Japiassu (2006) alerta para a questão quando as disciplinas ficam muito definidas e estabelecidas, e acabam formando círculos de comunicação entre os especialistas (embora necessário para o ensino e a pesquisa), podendo induzir a círculos fechados de poder, monopolizando o conhecimento em departamentos com características de poder, como lugares sagrados e intocáveis. Diante disso, devemos estar alertas e não se esquecer de algo que é importante "se tivemos que nos especializar para aprender, devemos nos abrir para compreender! Precisamos utilizar o máximo de nossa engenhosidade (ingenium) para religar, fazer convergir, contextualizar, representar os vínculos e as interações do que percebemos ou conhecemos" (JAPIASSU, 2006, p. 25, grifo do autor).

\section{Diálogo entre ciências e literatura}

Propor um diálogo entre ciências e literatura não parece ser uma tarefa comum aos olhos da objetividade. Segundo Galvão (2006), apesar de terem seus próprios métodos e linguagens, ambas as áreas tendem a proporcionar diversas leituras e perspectivas de análise quando postas em diálogo.

$\mathrm{Na}$ busca de suprir a lacuna da ciência como uma área objetiva, metodológica, inquestionável e estritamente especialista, Márquez (2010) aponta a literatura como uma forma de rever essa visão, oportunizando um suporte às aprendizagens baseadas em múltiplos significados por meio das metáforas, pois essas, por sua vez, contribuem para que os estudantes desenvolvam essa característica também em textos científicos. O contato com o mundo da ficção, ou os mundos imaginários, auxilia no desenvolvimento de mudanças conceituais. Para a pesquisadora venezuelana, basear-se em analogias e metáforas conhecidas para, a partir destas, criar novas metáforas torna-se um meio de explorar a criatividade dos alunos, inspirando-os a construir novas imagens e estruturas mentais, que transformam o ambiente e as leituras que fazemos dele.

Araújo (2007) aponta que os pressupostos epistemológicos vigentes nas teorias quânticas e biológicas atuais, como complexidade, causalidade linear, incerteza, intersubjetividade, dialogicidade, interatividade, autonomia, entre outros, condenam profundamente o modelo habitual cartesiano de construção de conhecimento por determinação linear, fragmentado e especialista.

Neste artigo, essas concepções trazem à discussão o estabelecimento de alguns exemplos característicos para que ocorra o diálogo interdisciplinar entre literatura e ciência na escola, contribuindo para um aprendizado mais satisfatório. 


\section{Análise do livro}

Para um diálogo entre literatura e ciências, como proposta interdisciplinar, será analisado o livro de Arthur Nestrovski (2002), vencedor do Prêmio Jabuti - Livro do ano de Ficção, Bichos que existem e bichos que não existem, em que o escritor apresenta, por meio de linguagem poética, a descrição dos seres que habitam nossa memória. A partir do conhecimento popular, que circula entre as crianças, ele descreve bichos que existem, como o jabuti, e outros que não existem (para a ciência), como o lobisomem.

Arthur Nestrovski, nascido em 1959, gaúcho de Porto Alegre, é diretor artístico da Orquestra Sinfônica do Estado de São Paulo, formado em música e pós-graduado (mestre e doutor) em música e literatura pela PUC-SP. Foi articulista da Folha de S. Paulo, editor da Publifolha. Dentre suas publicações, destacam-se: Notas musicais (2000), Outras notas musicais (2009), Palavra e sombra (2009), Histórias de avô e avó (1997/2010), Agora eu era (2009), Cores das cores (2006), Bichos que existem e bichos que não existem (2002). É também violonista e compositor, tendo gravado e se apresentado com Zé Miguel Wisnik, Ná Ozzetti, Zélia Duncan e Tom Zé.

Em Bichos que existem e bichos que não existem, por meio de uma reflexão divertida sobre realidade e imaginação, o autor brinca com o sentido das palavras de forma metafórica, aludindo aos bichos que existem e que não acreditamos, e a outros que não acreditamos que não existam. Contudo, ele destaca que não é a existência física ou não dos bichos que importa, pois todos existem, seja nos livros ou "na cabeça da gente" (NESTROVSKI, 2002, p. 7). Podemos perceber que essa forma divertida de introdução nos antecipa a ideia do que encontraremos nas próximas páginas, um livro não de ciências, não de biologia, nem de mitos, tampouco lendas ou história de bichos pré-históricos, mas de seres que permeiam nossas vidas e nossa imaginação, historietas que nos acompanham desde a tenra infância, recheadas por bichos temerosos ou esquisitos, até por seres cômicos que habitam o ciberespaço, materializando-se na literatura.

Na descrição do jabuti: "O jabuti é feio de rosto, mas bonito de corpo. Tem uma casca dividida em retângulos, com outros retângulos menores dentro. A casca é a casa dele" (NESTROVSKI, 2002, p. 7), observamos a concepção de bonito e feio, as diferenças subjetivas que cada sujeito possui desses adjetivos. $\mathrm{O}$ autor apresenta formas de falar sobre as estruturas anatômicas do jabuti, dizendo que a "casca é a casa dele" (Figura 1). 


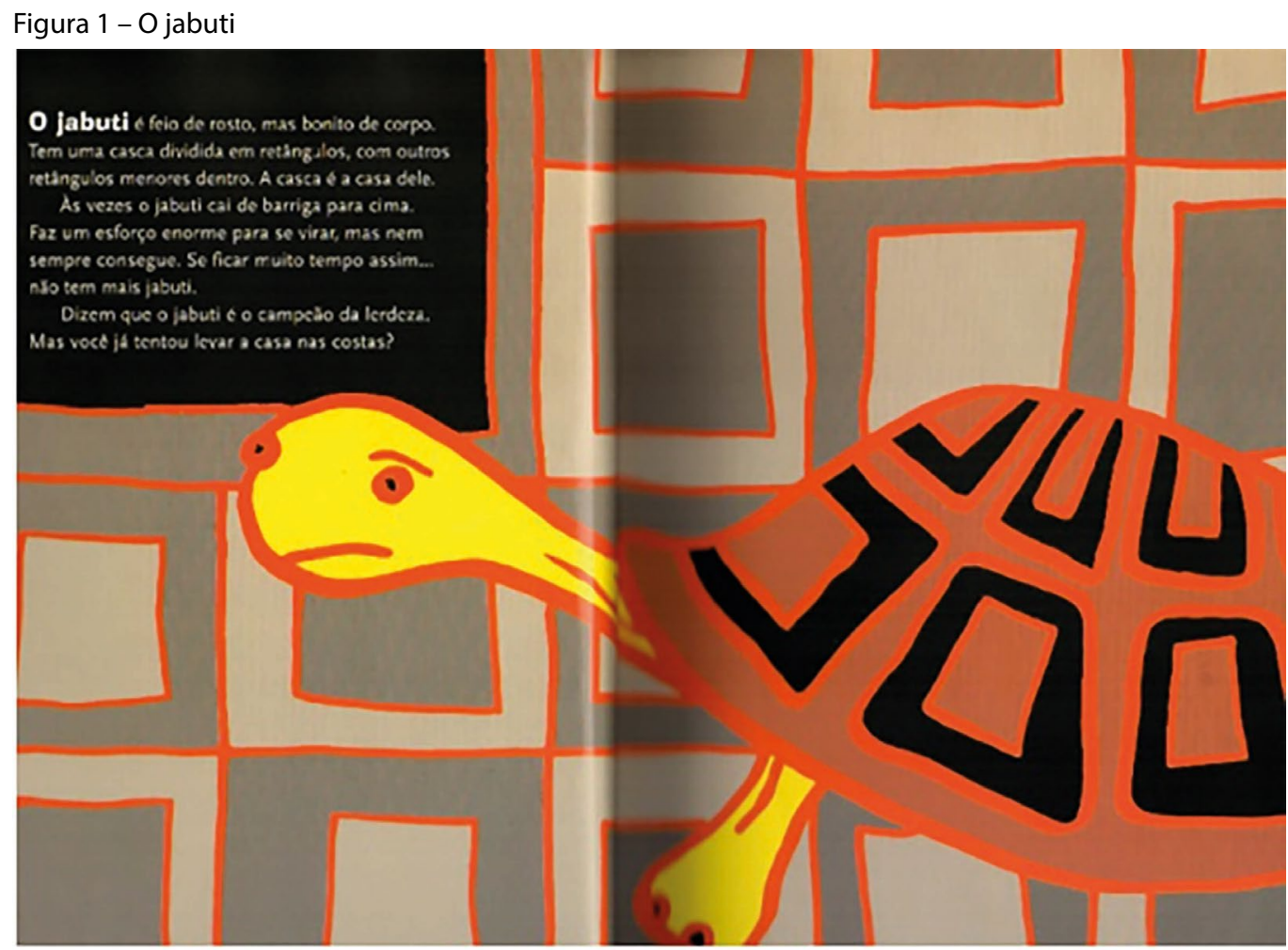

Fonte: Nestrovski (2002, p. 7-8).

A literatura tem a capacidade de brincar com as palavras consciente das limitações, muitas vezes, impostas pela linguagem. Ao trabalhar esses conceitos na ciência, podemos apresentar para os alunos uma realidade científica menos "dura", como costumeiramente a ciência clássica apresenta.

"Às vezes o jabuti cai de barriga pra cima. Faz um esforço enorme para se virar, mas nem sempre consegue. Se ficar muito tempo assim... não tem mais jabuti" (NESTROVSKI, 2002, p. 7, grifo nosso). Essa concepção de incerteza é fundamental para contradizer o pressuposto que, conforme Araújo, deve ser revisto no ensino de ciências:

[...] a formulação das práticas curriculares de ensino-aprendizagem, absolutizando apenas a razão e a experimentação, omitindo processos característicos subjetividades, assim como operando por seleção de dados significativos e rejeição de dados não significativos, da humanidade, como a emoção, as suas subjetividades, assim como operando por seleção de dados significativos e rejeição de dados não significativos (ARAÚJO, 2007, p. 516-517).

A maneira como a literatura aborda questões explicativas se torna interessante, pois estimula na criança um mundo imaginário. Exemplo disso ocorre quando 
o autor diz que o estômago do camelo é dividido em saquinhos, e que o camelo é o barco do deserto (Figura 2).

Figura 2 - O camelo

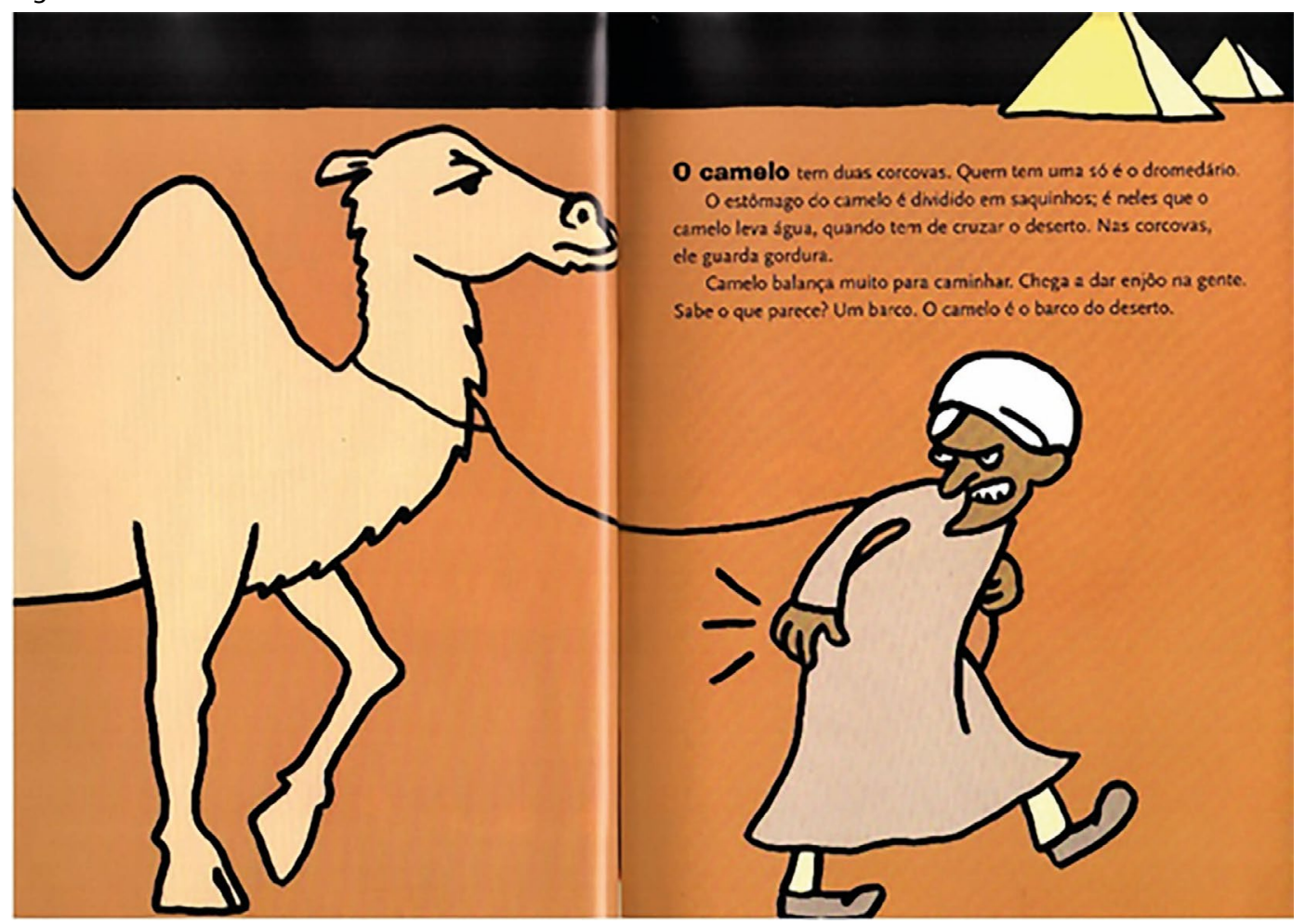

Fonte: Nestrovski (2002, p. 19-20).

Trabalhar conceitos da biologia de forma lúdica torna o processo de aprendizado mais atrativo para a criança do que a forma tradicional de ensino. De acordo com Ghedin et al., "[...] a fantasia, o irreal, o maravilhoso, ainda fazem parte do mundo da criança, por isso, ao trabalhar, por exemplo, conceito científico, pensa-se que o uso da literatura é de extrema importância, de maneira que a criança entrará em mundo imaginário, no qual toda sua atenção estará envolvida” (2013, p. 50).

O papel do professor é explorar a curiosidade natural das crianças para trabalhar a educação científica, pois elas têm a habilidade de construir perguntas mágicas em seus discursos, como: "Porque o camelo é marrom? O filhote do camelo tem corcovas? Como o camelo toma a água das corcovas?". As crianças têm uma visão mágica do mundo, que nós adultos não deveríamos perder.

Outro exemplo está, no livro, na apresentação do cavalo-marinho (Figura 3). 
Figura 3 - O cavalo-marinho

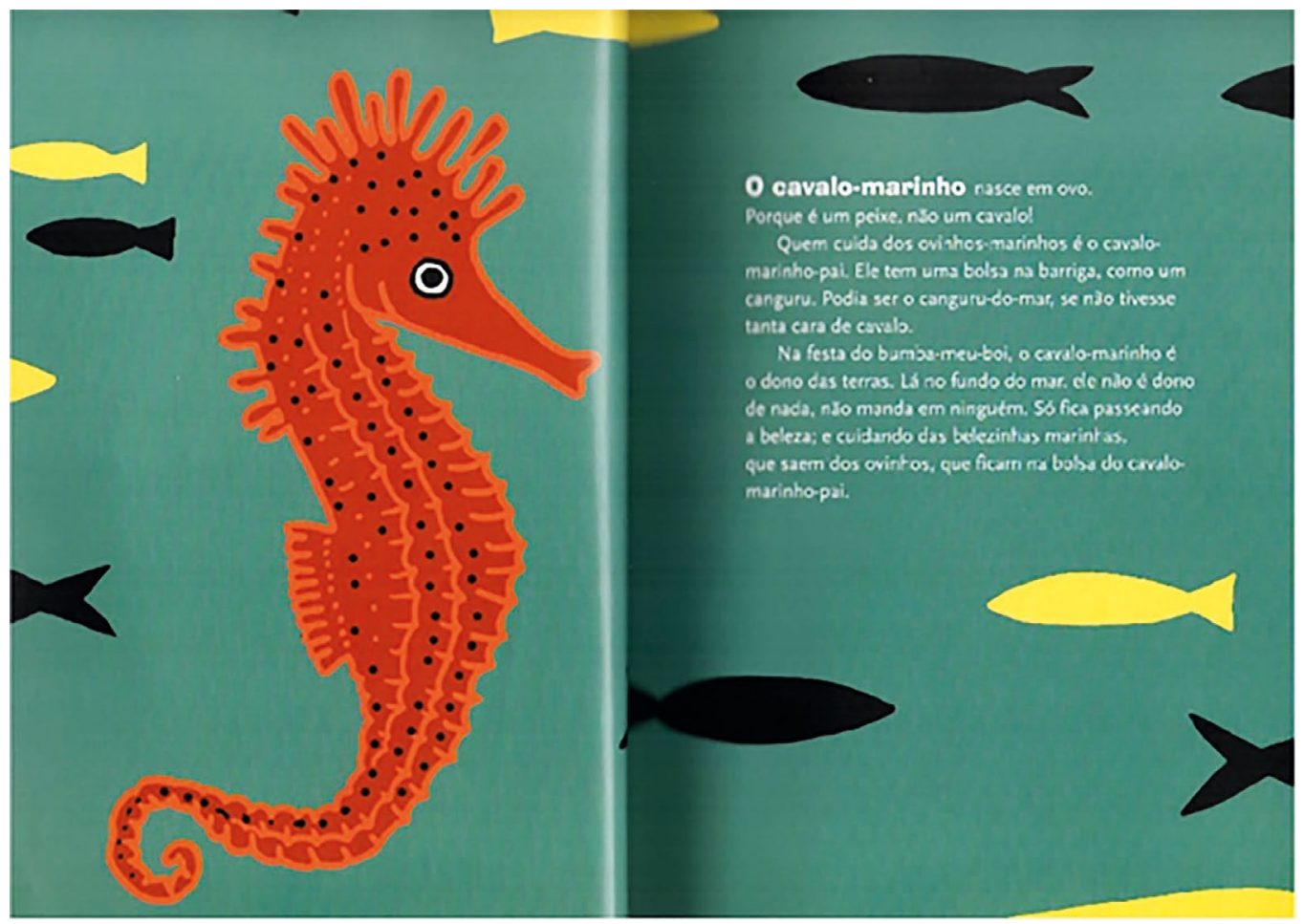

Fonte: Nestrovski (2002, p. 9-10).

A brincadeira com as palavras faz-se justamente com o nome do animal: um cavalo que vive no mar, entretanto, não é um cavalo, é um peixe que nasceu de um ovo. Na sabedoria da criança, como pode um cavalo (mamífero) viver embaixo d’água? Como consegue ele respirar? Além disso, o cavalo-marinho é uma mãe-canguru! Com muita familiaridade, Nestrovski apresenta essa diluição do gênero, comumente apresentado na sociedade como: pais (masculino) não cuidam dos filhos.

O modo como homens e mulheres se comportam em sociedade corresponde a um intenso aprendizado sociocultural que nos ensina a agir conforme as prescrições de cada gênero. Há uma expectativa social em relação à maneira como homens e mulheres devem andar, falar, sentar, mostrar seu corpo, brincar, danças, namorar, cuidar dos outros, amar, etc. Conforme o gênero, também há modos específicos de trabalhar, gerenciar outras pessoas, ensinar, dirigir o carro, gastar o dinheiro, ingerir bebidas, dentre outras atividades (BRASIL, 2009, p. 40).

Esses modelos estabelecidos socialmente, como atribuições femininas e masculinas, são (des/re)construídos no meio animal, por meio da linguagem poética. É graças ao poder imaginativo e criativo das crianças que o mundo se torna repleto de possibilidades. A realidade e a fantasia se fundem e se confundem, em plena 
harmonia, na subjetividade (literatura) e na razão (ciências). Evidências de possibilidades de fusão entre essas fronteiras propõem vazamentos da representação da racionalidade, permitindo a criação, como ocorre na definição da mula sem cabeça (Figura 4).

Figura 4 - A mula sem cabeça

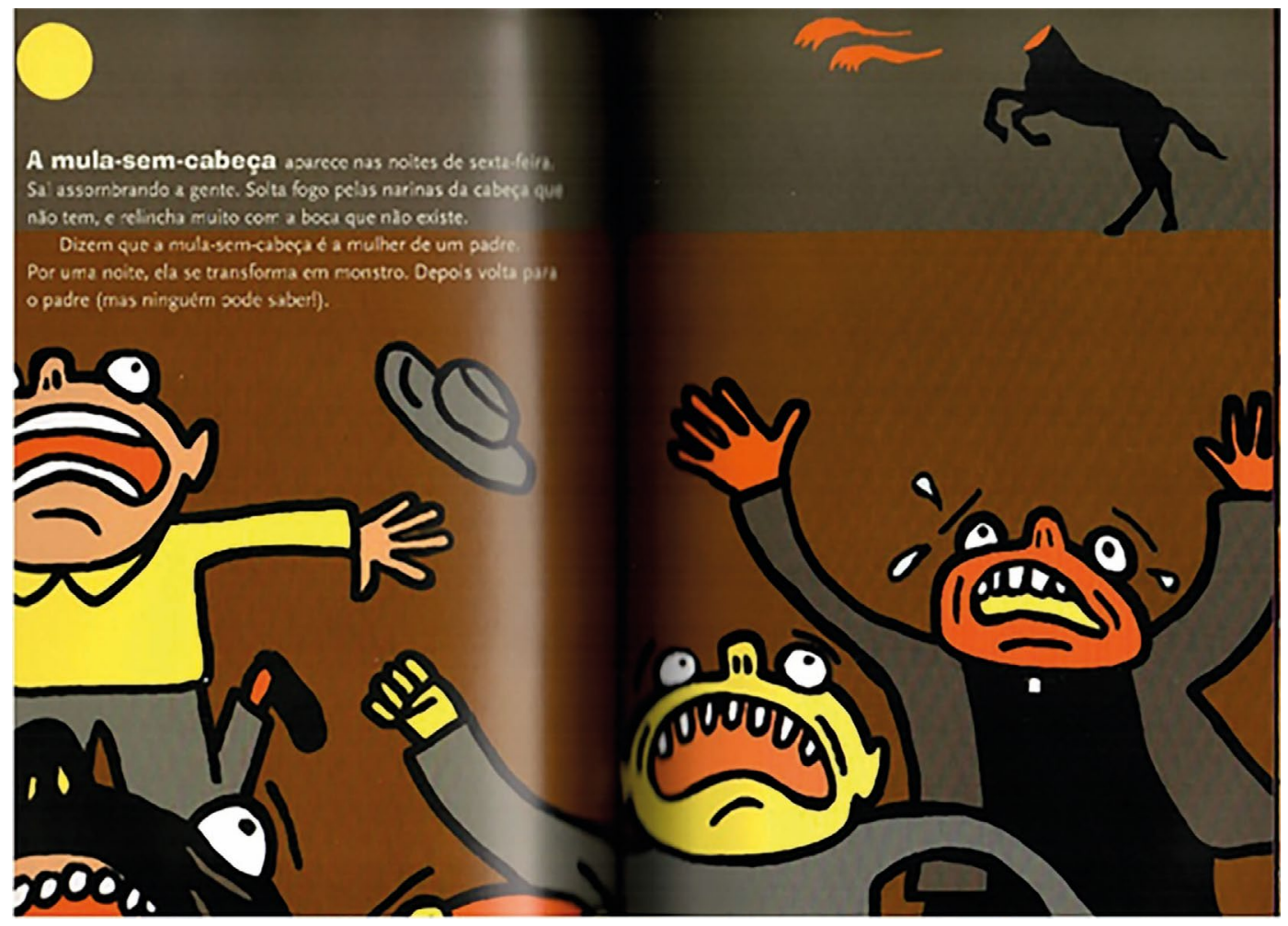

Fonte: Nestrovski (2002, p. 43-44).

Nesse sentido, segundo Santos (1999), o papel da literatura é oferecer incentivo ao mundo imaginário da fantasia, que possibilita ao estudante transitar na aventura da criação. Os contos literários despertam na criança o amor à beleza, contribuem para o desenvolvimento da imaginação, o poder da observação, favorecendo assim a ligação entre o mundo da fantasia e o da realidade. Fábulas e contos que despertam situações que estimulam os diferentes sentidos dos estudantes, envolvendo-os emocionalmente, facilitam o aprendizado, tendo em vista que quanto mais estímulos houver, mais a criança receberá condições para aquisição do conhecimento. 


\section{Considerações finais}

Em forma de apontamentos, procuramos realizar discussões sobre alguns fragmentos da obra de Nestrovski, sem pretensão de esgotar o assunto, mas com o intuito de explorar os fios que entrelaçam as disciplinas de ciências e literatura à luz de teóricos e concepções interdisciplinares.

Os exemplos que foram levantados neste trabalho evidenciam que a literatura favorece o entrelaçamento de conhecimentos interdisciplinares, sendo possível construir uma prática contundente, tornando o processo de ensino e aprendizagem das competências científicas um modo de prazer, descoberta, experimentação e exploração, ao invés da simples memorização de termos.

Assim, podemos dizer que o diálogo entre ciências e literatura como prática pedagógica interdisciplinar estabelece parâmetros que contribuem para um aprendizado mais condizente com as propostas didáticas contemporâneas de ensino, despertando nos estudantes o desejo de compreensão do conhecimento científico e a descoberta do novo.

\section{Interdisciplinarity: the science education through chidren's literature}

\section{Abstract}

The objective of this work is to bring to the discussion the possibility of building a practice in teaching science that addresses pleasurable activities of discovery, experimentation and exploration of scientific knowledge from the literature. We believe that the teaching of science combined with different working approaches awaken in students the desire for scientific knowledge and the discovery of the new. For this, we analyzed the children's book, Animal Farm that exist and animals that do not exist (NESTROVSKI, 2002), in which the writer presents through a poetic language, the description of these "beings" that inhabit our memory, since the tortoise to the werewolf. Through doubt, the desconstruction of this information is that the reader has the opportunity to transform the abstract into concrete, building different areas of interpretation, articulating fictional story to knowledge of biology. In that sense, we seek to ensure and suggest that the science of learning, once approached less harshly through the literary discourse, is more consistent with the thinking necessary renewal in the teaching of science.

Keywords: Children's Literature and Science. Education. Interdisciplinary.

\section{Nota}

1 Uma versão reduzida deste trabalho foi apresentada e publicada no Seminário Internacional sobre Interdisciplinaridade no Ensino, na Pesquisa e na Extensão - Região Sul. Florianópolis, 2013. 


\section{Referências}

ARAÚJO, M. M. S. O pensamento complexo: desafios emergentes para a educação on-line. Revista Brasileira de Educação, Rio de Janeiro, v. 12, n. 36, p. 515-551, set./dez. 2007.

BELTRÃO, C. S.; ROCHA FILHO, J. B. Eternamente Clarice: conexões entre o texto de Clarice, a psicologia analítica e a física. Porto Alegre: Cidadela, 2011.

BRASIL. Gênero e diversidade na escola: formação de professoras/es em gênero, orientação sexual e relações étnico-raciais. Livro de conteúdo. Versão 2009. Rio de Janeiro: Cepesc; Brasília: SPM, 2009.

CALVINO, I. Seis propostas para o próximo milênio: lições americanas. São Paulo: Companhia das Letras, 2011.

CEIA, C. Profissão: professor de literatura. EntreLetras, Araguaína, v. 3, n. 1, p. 195-214, jan./jul. 2012.

COMPAGNON, A. Literatura para quê? Belo Horizonte: Editora UFMG, 2009.

FEYERABEND, P. K. Contra o método. São Paulo: Unesp, 2007.

FURMAN, M. O ensino de ciências do ensino fundamental: colocando as pedras fundacionais do pensamento científico. São Paulo: Sangari Brasil, 2009.

GALVÃO, C. Ciência na literatura e literatura na ciência. Interacções, Lisboa, n. 3, p. 32-51, 2006.

GHEDIN, L. M. et al. A educação científica na educação infantil. Revista Amazônica de Ensino de Ciências, Areté, v. 6, n. 10, p. 42-52, 2013.

JAPIASSU, H. O sonho transdisciplinar: e as razões da filosofia. Rio de Janeiro: Imago, 2006.

LORENZETTI, L.; DELIZOICOV, D. Alfabetização científica no contexto das séries iniciais. Ensaio: Pesquisa em Educação em Ciências, Belo Horizonte, v. 3, n. 1, p. 37-50, 2001.

MACHADO, A. M. Contracorrente: conversas sobre leitura e política. São Paulo: Ática, 1999.

MÁRQUEZ, E. Análisis de estrategias de pensamiento complejo en adolescentes vulnerables social y académicamente. Tese (Doutorado em Educação) - Facultad De Humanidades Y Educación, Universidad De Los Andes, Venezuela, 2010.

MORIN, E. Introdução ao pensamento complexo. 4. ed. Porto Alegre: Sulina, 2011. Os sete saberes necessários à educação do futuro. São Paulo: Cortez, 2000.

NESTROVSKI, A. Bichos que existem e bichos que não existem. São Paulo: Cosac Naify, 2002.

SANTOS, I. S. Literatura infantil e interdisciplinaridade na sala de aula pré-escolar. Nuances, São Paulo, v. 5, n. 5, p. 126-131, jul. 1999.

SILVA, M. Literatura e experiência da vida: novas abordagens no ensino de literatura. Nau literária: crítica e teoria de literaturas, Porto Alegre, v. 6, n. 2, p. 1-10, jul./dez. 2010.

TODOROV, T. A literatura em perigo. Rio de Janeiro: Difel, 2009.

ZILBERMAN, R. A literatura infantil na escola. São Paulo: Global, 2003. 